\title{
Cd(II)の活性炭素繊維への吸着に及ぼす芳香族化合物の共存効果
}

\author{
千葉大学大学院工学研究科 古宿麻美 \\ 千葉大学大学院工学研究科, 千葉大学総合安全衛生管理機構 天野佳正・町田 基
}

\section{Effect of Coexisting Aromatic Compound for Cd(II) Adsorption onto Activated Carbon Fiber}

\author{
Mami Furuyado*1, Yoshimasa Amano ${ }^{* 1,2}$, and Motoi Machida ${ }^{* 1,2}$ \\ ${ }^{* 1}$ Graduate School of Engineering, Chiba University, 1-33 Yayoi-cho, Inage-ku, Chiba 263-8522, Japan \\ ${ }^{* 3}$ Safety and Health Organization, Chiba University, 1-33 Yayoi-cho, Inage-ku, Chiba 263-8522, Japan
}

\begin{abstract}
In this study, the effect of coexisting aromatic compound such as pyridine, aniline, indole, benzonitrile, phenol and benzoic acid on the Cd(II) adsorption onto activated carbon fibers (ACFs) was examined to identify which functional groups were effective for the adsorption. The results showed that the coexisting benzoic acid and pyridine were effective and increased the amount of $\mathrm{Cd}$ (II) adsorption at the $\mathrm{pH}$ of around 7 in the solution. On the other hand, the coexisting indole, aniline, phenol and benzonitrile caused the decrease in the amount of adsorbed Cd(II). These results suggest that carboxyl group (benzoic acid) and pyridine-N (pyridine) are more effective than pyrrole-N (indole), amino group (aniline), phenolic hydroxyl (phenol) and cyano group (benzonitrile) for the removal of Cd(II).
\end{abstract}

(Received 20 October, 2011 ; Accepted 12 January, 2012)

\section{1. 緒 言}

主に主に工場や廃棄物処分場から排出される重金属イ オンは, 毒性の強いものが多い。例えばカドミウムは非 分解性であるため体内に蓄積し, 腎障害や骨軟化症を引

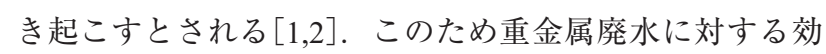
率的な処理技術の開発が必要とされている.

水溶液中の重金属イオンの除去方法として凝集沈殿, イオン交換，吸着，膜ろ過などがある[3]。中でも吸着は， スラッジの発生がなく, 比較的操作が簡便であるため, 新たな方法として広く注目されている[4]. 重金属イオン の吸着には，活性炭やゼオライトなど様々な吸着剤が用 いられている[5]。吸着剤のうち活性炭は，高い表面積を 持ち, かつ表面の修飾が可能である。形状も様々で粒状, 粉末状が主流であるが, 近年第三の活性炭として緎維状 活性炭が注目されている. 瀻維状活性炭は粒状活性炭と 比へ吸着速度も大きく再生し易い利点がある。活性炭は 芳香族化合物などの有機污染物質の吸着に非常に有効で あるのに対し, 重金属イオンの吸着量はその 50 分の 1 程 度である [6]. 従来の研究において, 活性炭への重金属イ オン吸着は, 表面に官能基を持たない活性炭に対しては, 活性炭上の $\pi$ 電子雲あるいはキノンやクロメンなどの塩 基性酸素との相互作用により吸着する。一方, 酸化処理 を施した活性炭には，活性炭表面に存在する酸性官能基 とのイオン交換により吸着する $[7,8]$ 。 また, 窒素含有活 性炭は窒素官能基の持つ非共有電子対との相互作用によ
り吸着すると考えられている[9]。このように活性炭表面 に官能基を導入することで, 重金属イオン吸着に対する 活性炭の性能向上が期待できる. しかし活性炭表面には 多数の官能基が存在しているため, どのような官能基が 重金属イオン吸着に有効に作用しているのか，はっきり とはわかっていない.

そこで本研究では, 重金属イオンと特定の官能基を持 つ芳香族化合物を共存させ, 活性炭素繊維 (Activated Carbon Fiber；ACF)への同時吸着を行った。活性炭へ吸着 しやすい芳香族化合物は ACF 一, 活性炭へ吸着し難い重 金属イオンは ACF に吸着した芳香族化合物表面の官能基 一吸着すると考え, 芳香族化合物と重金属イオンの同時 吸着を行い, $\mathrm{ACF}$ へ重金属イオンの吸着と吸着に有効 な官能基の特定を試みた。活性炭への芳香族化合物と金 属イオンの同時吸着に関する研究は多数報告されている [10-12]。しかしいずれの報告も吸着質の濃度や溶液 $\mathrm{pH}$ といった実験条件が異なり, 芳香族化合物の持つ官能基 の影響が正確に比較できない。またカルボキシル基をは じめ限られた官能基のみにて重金属イオンの吸着を評価 している報告がほとんどであるため, 重金属イオン吸着 に有効な官能基の種類について不明な点が多い. 本研究 では溶液 $\mathrm{pH}$ と共存芳香族化合物の吸着量を一定にした条 件で実験を行った。吸着質には重金属イオンの中でも特 に活性炭へ吸着し難い $\mathrm{Cd}$ (II) $[7,13]$ と, 特定の窒素官能基 あるいは酸素官能基を持つ芳香族化合物，すなわちピリ ジン(ピリジン窒素), アニリン(アミノ基), インドール(ピ 
ロール窒素), ベンゾニトリル(シアノ基), フェノール (フェノール性水酸基) 及び安息香酸 (カルボキシル基)を 用いた。

\section{2. 実験方法}

\section{1 吸着剤の物性}

吸着剂には市販の石炭ピッチ系活性炭素繊維 (A10, ユ ニチカ株式会社)を $900^{\circ} \mathrm{C}$ で 1 時間, ヘリウム雾囲気中で 脱気したものを使用した。使用した吸着剂の物性を Table 1 に示す。吸着剤の比表面積は，比表面積・細孔分布測定 装置(Beckman Coulter 製, SA3100)によって液体窒素温度 $\left(-196^{\circ} \mathrm{C}\right)$ における窒素吸脱着等温線を測定し, BET 法を 用いることで求めた。吸着剂の元素組成は, 元素分析装 置(Perkin-Elmer 製, Perkin-Elmer 2400)を用いて測定した。 吸着剂を粉砕し, $110^{\circ} \mathrm{C} て ゙ 1$ 時間乾燥させた。乾燥後の試 料 $1 \mathrm{mg}$ を，スズ箔に包んで $980^{\circ} \mathrm{C}$ で完全燃焼し C, H, N の含有率を得た。活性炭が吸湿性であることを考慮して, あらかじめ測定した吸湿水量を差し引いて各々の值を補 正した．活性炭の組成を C, H, N, O のみと仮定し，100\% から $\mathrm{C}, \mathrm{H}, \mathrm{N}$ の含有率の総量を差し引くことで $\mathrm{O}$ の含有 率を算出した。吸着剤の表面酸性官能基及び塩基性サイ トの定量は, 酸塩基滴定法を応用したBoehm [14]の方法 を用いて行った。吸着剤の表面電荷がゼロを示す $\mathrm{pH}$ $\left(\mathrm{pH}_{\mathrm{pzc}}\right)$ を測定するために, $0.1 \mathrm{~mol} / \mathrm{L}$ の塩化ナトリウム水 溶液 $25 \mathrm{~mL}$ に吸着剤 $0.05 \mathrm{~g}$ を加え, 塩酸と水酸化ナトリ ウム水溶液を用いて初期 $\mathrm{pH}$ を調整し，3 日間振とうさせ た後, 溶液の平衡 $\mathrm{pH}$ を測定した. 初期 $\mathrm{pH}$ と平衡 $\mathrm{pH}$ を プロットして平衡 $\mathrm{pH}$ が初期 $\mathrm{pH}$ と一致したところを $\mathrm{pH}_{\mathrm{pzc}}$ とした $[15]$.

\section{2 吸着実験}

溶液 $25 \mathrm{~mL}$ を $100 \mathrm{~mL}$ 三角フラスコに入れ, 吸着剂 $50 \mathrm{mg}$ を加えて $25^{\circ} \mathrm{C}, 100 \mathrm{rpm}$ で 24 時間振とうさせた. $\mathrm{Cd}(\mathrm{II})$

Table 1 Properties of ACFs.

\begin{tabular}{cc}
\hline Specific surface area $\left(\mathrm{m}^{2} / \mathrm{g}\right)$ & 1140 \\
\hline Elemental composition (wt $\%)$ & 95.5 \\
$\mathrm{C}$ & 0.08 \\
$\mathrm{H}$ & 0.58 \\
$\mathrm{~N}$ & 3.84 \\
\hline $\mathrm{O}^{\mathrm{a})}$ & \\
Surface functional groups (meq./g) & \\
Acidic sites & 0.00 \\
carboxylic (-COOH) & 0.04 \\
lactonic (-COO-) & 0.51 \\
phenolic (Ar-OH) & 1.03 \\
\hline Basic sites & 7.3 \\
\hline $\mathrm{pH}_{\mathrm{pzc}}$
\end{tabular}

a) Calculated by difference
Table 2 Physico-chemical properties of the aromatic compounds used in this study.

\begin{tabular}{lccc}
\hline \multirow{2}{*}{ Aromatic compound } & \multicolumn{2}{c}{ Solubility in water $^{\mathrm{a})}$} & \\
\cline { 2 - 4 } & $\mathrm{wt} \%$ & & \\
\hline pyridine & $\infty$ & 5.23 & $1.34^{\mathrm{b})}$ \\
aniline & $3.38\left(25^{\circ} \mathrm{C}\right)$ & 4.87 & $0.10^{\mathrm{b})}$ \\
indole & $0.19\left(20^{\circ} \mathrm{C}\right)$ & - & - \\
benzonitrile & $0.20\left(25^{\circ} \mathrm{C}\right)$ & - & - \\
phenol & $8.66\left(25^{\circ} \mathrm{C}\right)$ & 9.99 & - \\
benzoic acid & $0.34\left(25^{\circ} \mathrm{C}\right)$ & 4.20 & $1.04^{\mathrm{c})}$ \\
\hline
\end{tabular}

a) [16], b) [17], c) [18],

$\log \mathrm{K}$; complex formation constant

の吸着に対し，吸着剤における表面電荷の影響が大きい ことから,すべての実験において溶液の平衡 $\mathrm{pH}$ が $\mathrm{pH}_{\mathrm{pzc}}$ 付近の 6-7 になるように初期 $\mathrm{pH}$ を硝酸，あるいは水酸化 ナトリウムを用いて調整した. 芳香族化合物の濃度は UVVis 分光光度計(島津製作所製, UV 2550)にて, Cd(II)の 濃度は原子吸光光度計(アナリティクエナ製, novAA300)

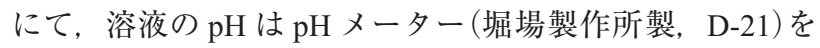
用いて測定した。なお，使用した芳香族化合物の物性は Table 2 に示す通りである.

\subsection{1 芳香族化合物の吸着}

芳香族化合物はピリジン，アニリン，フェノール，安 息香酸，インドール及びベンゾニトリルを用いた．それ ぞれの初濃度を $50-2000 \mathrm{mg} / \mathrm{L}$ に変化させ, 吸着等温線を 求めた. さらに, 芳香族化合物の平衡濃度 $\mathrm{C}_{\mathrm{e}}(\mathrm{mmol} / \mathrm{L})$ 及 び平衡吸着量 $\mathrm{Q}_{\mathrm{e}}(\mathrm{mmol} / \mathrm{g})$ を以下の Langmuir 式に当てはめ, 最大吸着量 $X_{m}(\mathrm{mmol} / \mathrm{g})$ 及び吸着親和力 $K_{e}(\mathrm{~L} / \mathrm{mmol})$ を算出 した。

$$
\frac{C_{e}}{Q_{e}}=\frac{C_{e}}{X_{m}}+\frac{1}{X_{m} K_{e}}
$$

\subsubsection{Cd(II) と芳香族化合物の同時吸着}

$\mathrm{Cd}(\mathrm{II})$ の吸着量は, 芳香族化合物の初濃度に影響を受け ると考えられるため, 吸着実験で用いる溶液の芳香族化 合物の初濃度を 50-2000 mg/L に変化させた. Cd(II)の初 濃度は $100 \mathrm{mg} / \mathrm{L}$ に調整した。また芳香族化合物のみを吸 着させた場合と比較するため, 2.2.1 と同様に芳香族化合 物と $\mathrm{Cd}(\mathrm{II})$ を共存させ吸着させた場合の芳香族化合物の $X_{m}(\mathrm{mmol} / \mathrm{g})$ 及び $K_{e}(\mathrm{~L} / \mathrm{mmol})$ を算出した.

\section{3. 結果と考察}

\section{1 芳香族化合物の吸着}

溶液中の芳香族化合物の初濃度を $50-2000 \mathrm{mg} / \mathrm{L}$ に変化 させたときの芳香族化合物単体の吸着等温線を Fig. 1 に示 す. 芳香族化合物の吸着量は, インドール>ベンゾニト リル $\geq$ アニリン $\geq$ フェノール $>$ ピリジン $\geq$ 安息香酸の順 
になった，これは安息香酸を除いて，Table 2 に示した水 への溶解度の低い順, 即ち疎水性の順とほほ一致する. 吸着剂表面も疎水性と考えられるので, 芳香族化合物の 疎水性が大きい程, 疎水性表面に吸着し易くなると解釈 できる．また安息香酸の $\mathrm{pK}_{\mathrm{a}}$ が 4.2 であることから, 溶液 の平衡 $\mathrm{pH}$ が 6-7 付近では, 下記の式の平衡がイオン種側 に片寄っている.

$$
\mathrm{Ph}-\mathrm{COO}^{-}+\mathrm{H}^{+} \rightleftarrows \mathrm{Ph}-\mathrm{COOH}
$$

Table 1 に示すように本研究で用いた ACF の $\mathrm{pH}_{\mathrm{pzc}}$ が 7.3 であることから，溶液中において ACF の表面は負電荷よ りになっている。このため, 安息香酸におけるカルボキ シル基の負電荷と $\mathrm{ACF}$ 表面の負電荷間の静電的な反発に より, 安息香酸の吸着量が他の芳香族化合物と比べて低 くなったと考えられる.

\section{$3.2 \mathrm{Cd}(\mathrm{II})$ と芳香族化合物の同時吸着}

Table 3 に各芳香族化合物の吸着等温線 (Fig. 1) から求め た $X_{m}$ と $K_{e}$ および芳香族化合物と $\mathrm{Cd}(\mathrm{II})$ を共存させたと

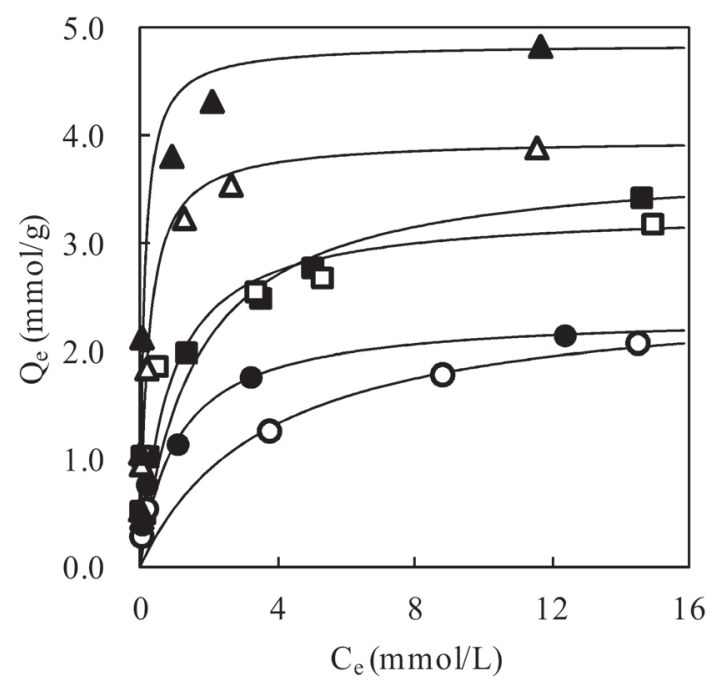

Fig. 1 Adsorption isotherms of aromatic compounds $(0.05 \mathrm{~g}$ ACFs in $25 \mathrm{~mL}$ solution agitated for 24h). $\Delta$ : indole, $\triangle$ : benzonitrile, $\square$ : aniline, $\square$ : phenol, $\bigcirc$ : benzoic acid, $\bigcirc$ : pyridine
きの $X_{m}, K_{e}$ を示す. $\mathrm{Cd}(\mathrm{II})$ の有無に関わらず芳香族化合

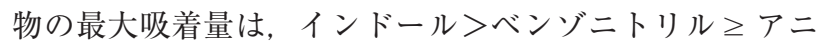
リン $\geq$ フノール>ピリジン $\geq$ 安息香酸の順になった。 また吸着親和力にも大きな違いは見られなかったことか ら, 芳香族化合物の吸着に対する Cd(II)の影響は小さく, 活性炭へ吸着しやすい芳香族化合物は ACF , 活性炭へ 吸着し難い $\mathrm{Cd}(\mathrm{II})$ は全吸着量の一部が芳香族化合物の有 する特定の官能基へ吸着することが期待できる.

それぞれの芳香族化合物の吸着量が一定 (約 $2 \mathrm{mmol} / \mathrm{g}$ ) のときの $\mathrm{Cd}$ (II) の吸着量を Fig. 2 に示す. 安息香酸と $\mathrm{Cd}$ (II)の同時吸着に関して, 安息香酸の吸着量が $2.1 \mathrm{mmol} / \mathrm{g}$ のとき, $\mathrm{Cd}(\mathrm{II})$ の吸着量が $0.3 \mathrm{mmol} / \mathrm{g}$ と, 安息香酸が存 在しないときと比べて 3 倍以上となった。 これは, FaurBrasquet ら [10]が示すように安息香酸の持つカルボキシル 基と $\mathrm{Cd}(\mathrm{II})$ のイオン交換が起こったと考えられ， Cd(II) 吸着にカルボキシル基が有効であることが明らかになっ た. 次いで, ピリジンと $\mathrm{Cd}(\mathrm{II})$ の同時吸着に関して, 安 息香酸には劣るがピリジンが存在するとピリジンが存在

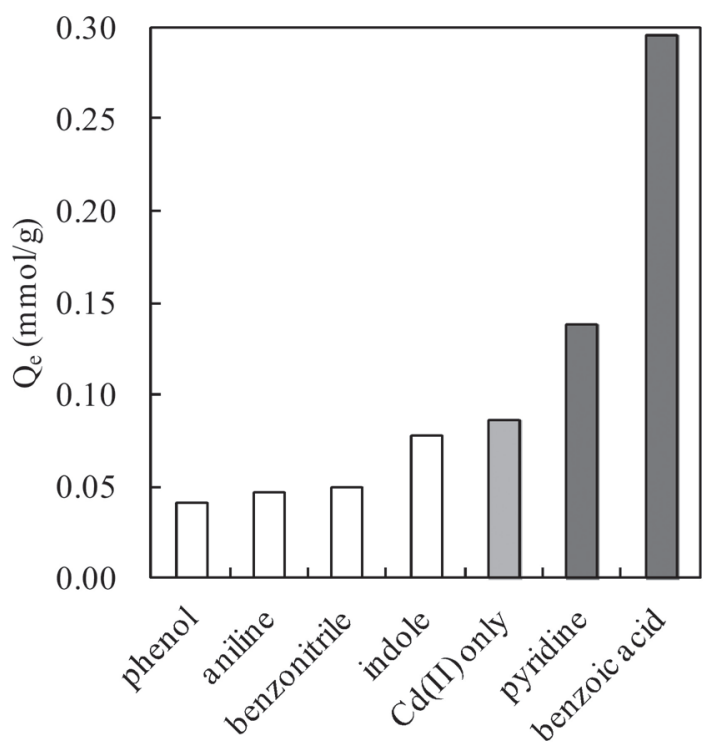

Fig. 2 Amounts of Cd(II) adsorption in the presence of adsorbed aromatic compounds at $2 \mathrm{mmol} / \mathrm{g}$.

Table 3 Langmuir parameters for the aromatic compounds adsorption in the absence and the presence of $\mathrm{Cd}(\mathrm{II})$.

\begin{tabular}{|c|c|c|c|c|c|c|}
\hline \multirow{3}{*}{ Aromatic compound } & \multicolumn{3}{|c|}{ Aromatic compound only } & \multicolumn{3}{|c|}{ Aromatic compound $+\mathrm{Cd}(\mathrm{II})$} \\
\hline & $X_{m}$ & $K_{e}$ & $\mathrm{R}^{2}$ & $X_{m}$ & $K_{e}$ & $\mathrm{R}^{2}$ \\
\hline & $\mathrm{mmol} / \mathrm{g}$ & $\mathrm{L} / \mathrm{mmol}$ & - & $\mathrm{mmol} / \mathrm{g}$ & $\mathrm{L} / \mathrm{mmol}$ & - \\
\hline indole & 4.86 & 8.64 & 0.999 & 4.71 & 11.9 & 0.999 \\
\hline benzonitrile & 3.96 & 4.41 & 0.999 & 3.89 & 4.41 & 0.999 \\
\hline aniline & 3.77 & 0.64 & 0.998 & 3.85 & 0.80 & 0.995 \\
\hline phenol & 3.32 & 1.22 & 0.996 & 3.53 & 1.72 & 0.993 \\
\hline pyridine & 2.55 & 0.27 & 0.998 & 2.23 & 0.52 & 0.999 \\
\hline benzoic acid & 2.35 & 0.94 & 1.000 & 2.18 & 0.81 & 0.993 \\
\hline
\end{tabular}


しないときと比較して, $\mathrm{Cd}(\mathrm{II})$ の吸着量が 1.5 倍以上増加 した。これはピリジンの持つ非共有電子対との配位によ り $\mathrm{Cd}(\mathrm{II})$ の吸着量が増加したと考えられる. 逆に, イン ドール，ベンゾニトリル，アニリンおよびフェノールと Cd(II)の同時吸着では, $\mathrm{Cd}(\mathrm{II})$ 吸着量が減少した. Fig. 2 には示していないが, これらの芳香族化合物の吸着量を さらに増やしていくと Cd(II)が全く吸着しなくなった. このことは芳香族化合物の官能基と Cd(II)の親和性が低 いばかりでなく, 芳香族化合物が $\mathrm{ACF}$ 上の $\mathrm{Cd}(\mathrm{II})$ 吸着サ イトの一部を占有していることを示している．以上の結 果から，芳香族化合物と $\mathrm{Cd}(\mathrm{II})$ は吸着サイトを奪い合っ ており, 芳香族化合物の官能基と Cd(II) との親和性が高 いときのみ，吸着した芳香族化合物が $\mathrm{Cd}(\mathrm{II})$ と錯体を生 成して Cd(II) 単独の場合よりも Cd(II) 吸着量が増加する と解釈できる. 官能基の親和性については, 例えばアニ リンについては Table 2 に示したように錯生成定数 $(\log \mathrm{K})$ が安息香酸やピリジンと比べて 1 ケ夕以上小さいことか らも支持される.

\section{4. 結 論}

本研究では, 活性炭素繊維を吸着剤として, $\mathrm{Cd}(\mathrm{II})$ と特 定の官能基を持つ芳香族化合物の同時吸着を行った，得 られた知見は以下の通りである.

・本実験条件下において, $\mathrm{Cd}(\mathrm{II})$ 水溶液に安息香酸やピリ ジンが共存すると活性炭素繊維への吸着は Cd(II) 単独 で吸着したときと比べてそれぞれ 3 倍, 1.5 倍以上 $\mathrm{Cd}$ (II) 吸着量が増加した. 一方, インドール, アニリン, フェノールおよびベンゾニトリルが共存すると最大で $\mathrm{Cd}(\mathrm{II})$ 吸着量が 2 分の 1 に減少した。

$\cdot \mathrm{Cd}(\mathrm{II})$ と芳香族化合物を共存させると, 芳香族化合物が $\mathrm{Cd}$ (II) 吸着サイトの一部を占有するため吸着が阻害され て Cd(II) 吸着量の減少が観察されるが, カルボキシル 基やピリジン窒素など芳香族化合物の持つ官能基と $\mathrm{Cd}$ (II)の親和性が高い場合には, 活性炭素繊維上に吸着し た芳香族化合物の官能基と $\mathrm{Cd}(\mathrm{II})$ がさらに錯体を生成 して Cd(II)吸着量が増大すると考えられる.

\section{謝 辞}

本研究の一部は, 日本学術振興会・科学技術研究費補 助金・基盤研究 C「水質污染物質の吸着・分解除去のた めの高性能活性炭の設計(No. 23510091)」の助成を受けた ものです．また本研究を進めるにあたり，多くのご助言 を頂きました木更津工業高等専門学校の相川正美教授(理 学博士)，多岐にわたるご支援をいただきました千葉大学 総合安全衛生管理機構の長尾啓一機構長 (教授, 医学博士) に厚く御礼申しあげます。

\section{文 献}

1. M. Li, T. Kondo, Q. Li Zhao, F. J. Li, K. Tanabe, Y. Arai, Z. C. Zhou, and M. Kasuya, J. Biol. Chem., 275, 39702 (2000).

2. D. Mohan, C. U. Pittman Jr., M. Bricka, F. Smith, B. Yancey, J. Mohammad, P. H. Steele, M. F. AlexandreFranco, V. Gómez-Serrano, and H. Gong, J. Colloid Interface Sci., 310, 57 (2007).

3. K. Urano, “Anzenkougakukouza 8 suishitsuodaku dojouosen”, (Anzenkougakukyoukai, Ed.), Kaibundoushuppan, Japan, p.203 (1982).

4. Y. Kong, J. Wei, Z. Wang, T. Sun, C. Yao, and Z. Chen, J. Appl. Polym. Sci. 122, 2054 (2011).

5. F. Fu, and Q. Wang, J. Environ. Manage., 92, 407 (2011).

6. S. Sato, K. Yoshihara, K. Moriyama, M. Machida, and H. Tatsumoto, Appl. Surf. Sci., 253, 8554 (2007).

7. K. Yoshihara, M. Machida, and H. Tatsumoto, J. Environ. Chem., 19, 187 (2009).

8. R. Leyva-Ramos, P. E. Diaz-Flores, A. Aragon-Piña, J. Mendoza-Barron, and R. M. Guerrero-Coronado, Sep. Sci. Technol., 40, 2079 (2005).

9. R. Okayama, Y. Amano, and M. Machida, Tanso, 242, 45 (2010).

10. C. Faur-Brasquet, K. Kadirvelu, and P. L. Cloirec, Carbon, 40, 2387 (2002).

11. M. Pakuła, M. Walczyk, S. Biniak, and A. Świątkowski, Chemosphere, 69, 209 (2007).

12. J. Lach, E. Okoniewska, E. Neczaj, and M. Kacprzak, Desalination, 223, 249 (2008).

13. K. Wilson, H. Yang, C. W. Seo, and W. E. Marshall, Bioresour. Technol., 97, 2266 (2006).

14. H. P. Boehm, Carbon, 40, 145 (2002).

15. P. C. C. Faria, J. J. M. Orfao, and M. F. R. Pereira, Water Res., 38, 2043 (2004).

16. "CRC Handbook of Chemistry and Physics, 82nd Edition", (D. R. Lide, Ed.), CRC, Washington, DC (2001).

17. "Critical Stability Constants Volume 2: Amines", (A. E. Martell, and R. M. Smith, Ed.), Plenum, New York (1989).

18. "Critical Stability Constants Volume 3: Other Organic Ligands", (A. E. Martell, and R. M. Smith, Ed.), Plenum, New York (1989). 